\title{
¿Por amor al arte? Creación artística y mercado, oportunidades y dificultades
}

\section{JUST FOR NOTHING? ARTISTIC CREATION, MARKET, OPPORTUNITIES AND DIFFICULTIES}

María del Carmen Laredo

Instituto Superior de Artes Visuales Edith Sachs

\section{RESUMEN}

En nuestra época, la creación artística local se ha diversificado dejando atrás su uniformidad para dar pase a lo variado y heterogéneo, y a la vez ha visto multiplicados los espacios para su difusión. Estos fenómenos obedecen a múltiples factores, entre los que se encuentra la concepción de los productos artísticos como ofertas que entran en la dinámica del mercado 0 que se conciben y expresan para comunicar, apoyándose, además, en la tecnología disponible. Basándome en mi experiencia como artista plástica peruana, pretendo reflexionar acerca de los diferentes tipos de arte, específicamente el actual, y las dificultades, límites y exigencias que esta situación plantea a la creación artística local, pero también sobre las oportunidades que ofrece el contacto abierto entre artistas y sociedad, que puede 0 debería enriquecer los procesos creativos. En suma, las preguntas renovadas son qué es arte y qué se requiere para crear objetos artísticos.

PALABRAS CLAVE: creación artística, objetos de arte, mercado artístico, tecnología para el arte

\section{ABSTRACT}

In our time, the local artistic creation has diversified leaving behind its uniformity to give way to the varied and heterogeneous, in the same way the spaces have also been multiplied for their diffusion. These phenomena are due to multiple factors including the conception of artistic products as offers that enter the market dynamics or are conceived and expressed to communicate supported by the technology available. Based on my personal experience as a Peruvian plastic artist, I intend to reflect on the different types of art, specifically the present and the difficulties, limits and demands that this situation poses to artistic creation, but also the opportunities offered by the open contact between artists and society that can or should enrich the creative processes. In conclusion, the renewed questions are what is art and what is required to create artistic objects.

KEYWORDS: artistic creation, art objects, artistic market, technology for art 


\section{INTRODUCCIÓN}

Hace poco, mientras me encontraba en mi taller ubicado en Miraflores preparando unos cuadros para enviarlos a un concurso de arte convocado por el Qorikancha del Cusco, se contactaron conmigo por WhatsApp para preguntarme si estaba interesada en escribir un artículo relacionado con el arte para una revista. Como era de esperar, mi respuesta afirmativa fue inmediata.

Después de la primera impresión y percatándome de mi ímpetu, noté que necesitaba conocer ciertos parámetros para desarrollarlo. Ante tal situación, escribí para hacer la respectiva consulta y obtuve la siguiente respuesta:

El tema es libre, es arte en el Perú, en cualquier tiempo, en cualquier soporte, con cualquier artista, con cualquier estilo, puede ser un estilo, tratarse de un artista, tratarse de una moda, tratarse de un soporte, de una escuela, de una sola obra, de una comparación de obras, en realidad el tema es infinito.

Sentada y bebiendo un café en la sala de mi casa, pensé: “ ¡Qué buena oportunidad! ¡Por fin podré mostrar mi texto sobre el uso del dorado a la hoja como soporte y técnica en las artes plásticas peruanas actuales que redacté hace años!". Lo hice en el tiempo cuando me dedicaba íntegramente a la restauración de obras de arte, pero, por diferentes motivos, no había podido mostrarlo y quedó guardado en el baúl de los recuerdos esperando el momento justo para ser revelado.

Puedo asegurar que lo más interesante sucedió a continuación. Durante los siguientes dos días y tras una ardua búsqueda, el bendito documento no aparecía por ningún lugar. La situación en la que me encontraba me hizo reflexionar sobre qué hacer, qué escribir, puesto que habían pasado cuatro años desde que lo redacté y sucedía que mi tema de interés había cambiado. Ahora estaba más involucrada en crear obras de arte, a diferencia de mi anterior actividad que era la restauración de dichas obras.

Al tercer día, después de una gran incertidumbre, sentada frente a la computadora, me descubrí interiorizando sobre mis nuevos intereses. Sentí que era sensato escribir sobre una situación que me venía sucediendo desde que retomé mi vocación. Me refiero a la búsqueda interna de respuestas ante preguntas vinculadas al arte.

Esa misma tarde, tras una lluvia de ideas sobre el tema que iba a tratar, comencé a escribir las primeras palabras y frases que me ayudarían a responder preguntas tales como ¿qué es arte?, ¿qué es el arte actual?, ¿quiénes determinan si mi obra es arte?, ¿tengo que conocer gente que me promocione en el círculo artístico?, ¿qué voy a crear?, ¿qué me conviene crear?, ¿debo crear para vender y adornar una sala o debo crear para expresar, aunque eso signifique no vender una sola obra?, ¿a qué público va a ir dirigida mi obra?, ¿figurativo, abstracto, surreal, puntos o cuadrados?, ¿full color, blanco, negro o 
gris? Me fui a la cama pensando que me estaba sumergiendo en un tema muy extenso y que tenía que enfocarlo a resolver la búsqueda personal que tanto anhelaba.

Al día siguiente, después de una larga caminata por el malecón, pude ubicar el momento exacto en que la mayoría de las interrogantes sobre el arte comenzaron a aparecer. Puedo afirmar con seguridad que todo inició desde que retomé a mediados del 2016 mi actividad artística, que se había interrumpido cuando tuve la oportunidad de estudiar restauración de obras de arte por medio de una beca.

A manera de paréntesis, resaltaré que en un primer momento dudé en dejar mi vida artística, puesto que hay una gran diferencia entre crear y restaurar obras de arte. Esta desemejanza consiste básicamente en la inventiva y comunicación que el artista plasma en sus obras nuevas, en contraposición a la actividad de un restaurador, que trata sobre el uso de técnicas de manufacturas ancestrales sobre un bien ya existente.

Abreviando la situación, comentaré que consideré los pros y contras, me aventuré y mi vida en los últimos años la dediqué a trabajar en todo lo concerniente a la restauración de obras de arte, monumentos arquitectónicos e incluso arqueológicos, hasta que el arte se abrió camino y tímidamente empecé a asistir a exposiciones, galerías, leer algunos libros de arte y llevar uno que otro curso. Recuerdo que al principio me sentí bastante desubicada e insegura para empezar a crear de nuevo, cuestión que no me sucedía hace catorce años, cuando no tenía dudas y simplemente dejaba que la obra fluyera de acuerdo con lo que pensaba o sentía en el momento de elaborarla.

Acerca de mi búsqueda personal y casi mística sobre el tema artístico, diré que en un primer momento todo el conocimiento y la información valiosa que se presentó ante mí ingresó de manera violenta, desordenada, con respuestas ambiguas que poco a poco fui organizando según mi interés para ser compartidas. El entendimiento que he adquirido en la actualidad está basado en la información que conseguí en libros, revistas, internet, experiencias personales y sobre todo en conversaciones con amigos. Todos estos elementos me ayudaron para aclarar momentáneamente temas como el arte, la creación artística, la diversificación de la creación artística, la tecnología en el arte, los espacios expositivos y el mercado del arte. Empleo la palabra momentáneamente porque según mi experiencia personal con el paso del tiempo suelen surgir nuevas interrogantes.

Una de las primeras acciones que realicé para recopilar información fue navegar por internet con el objetivo de saber de manera inmediata qué opinaban algunos entendidos en la materia. La primera página que me llamó la atención fue una entrevista del año 2013 a Donald Kuspit, conocido crítico de arte, doctor en Historia del Arte por la Universidad de Míchigan, doctor en Filosofía por la Universidad de Yale y la Universidad de Fráncfort, además de profesor de Historia del Arte y Filosofía en la Universidad Estatal de Nueva 
York y ganador del prestigioso Premio Frank Jewett Mather, concedido por la College Art Association. Consideré que con tantos logros en su hoja de vida era importante leer con atención lo que él tenía que decir.

En la entrevista, Kuspit agradece su más reciente reconocimiento, el Premio Gabarrón de Pensamiento y Humanidades, y hace una observación sobre el desenvolvimiento de la crítica y los críticos de antaño (Baudelaire, Greenberg, Rosenberg y Steinberg). Considera que fueron formados para dicho fin como intelectuales, conocedores de su historia, con la capacidad de evaluar y hacer crítica de arte, en contraposición al estado del arte denominado contemporáneo que, en su opinión, por algunos factores carece de un análisis intelectual, reflexión y valoración de su lugar en la sociedad. Kuspit opina:

Esto se debe al menos a dos factores: la idea posmoderna de que "todo vale", que supone la supresión de cualquier jerarquía de los valores artísticos y el colapso del típico cliché del arte avant-garde o experimental, y el hecho de que escribir sobre el arte se haya convertido en un tema más propio de los medios de comunicación que de análisis y reflexión.

También señala que los críticos actuales se encuentran atados a una industria cultural globalizada, donde el arte es visto como un producto con valor monetario que sube en función de la cantidad de exposiciones que tiene el artista, y llega incluso a convertirse en una marca. Esto trae consigo la aparición de lo que él llama seudoartistas $y$, a su vez, ocasiona la duda sobre el concepto de arte.

A continuación, encontré en el portal de la Universidad de Barcelona (UB) una entrevista a Vicenç Furió, profesor de Teoría y Sociología del Arte del Departamento de Historia del Arte de esa casa de estudios, en el marco de la publicación de su nuevo libro Arte y reputación. Estudios sobre el reconocimiento artístico (2012). Ante la pregunta del reportero sobre el tema de la reputación del artista, Furió comenta que en sus inicios muchos artistas (tanto actuales como del pasado) no son tan valorados en la industria artística hasta después de volverse mediáticos, apareciendo en varias publicaciones, periódicos, revistas, televisión, exposiciones y libros de arte. Además, indica que la construcción de la reputación de un artista depende siempre de alguien: "Hay distintas instancias de reconocimiento: los propios artistas, los críticos, los museos, los historiadores de arte y el mundo académico, el mercado, los comisarios, etcétera".

Respecto a la construcción de la reputación de un artista, Furió señala que hay artistas que son muy cotizados en el mercado del arte, lo que trae consigo que personas vinculadas a este mercado (galeristas y coleccionistas) los defiendan y difundan que su obra es muy buena. Destaca, sin embargo, que el ser cotizado en el mundo del arte no es garantía de permanencia a lo largo de la historia. En tal sentido, considera que entre las obras clásicas el asunto de la reputación se encuentra en un continuo vaivén que depende de la época y las circunstancias que las vinculan con el momento que se vive, 
a excepción de las obras de Leonardo, Rafael, Giorgione, Tiziano y Rubens, que por su condición de académicas son constantes e inamovibles.

Al finalizar la segunda lectura, noté que ambos autores coincidían en una característica algo inquietante en el entorno artístico global: el hecho de que existe una industria artística manejada por ciertos personajes para hacer que un producto (artista y obra) alcance cierto nivel de aprobación para ser vendible, y emplea para ello la exposición mediática. Por la noche, decidí que era momento de llevar a cabo un trabajo de campo, así que hice un par de llamadas a unos amigos artistas para que me acompañaran al día siguiente a un recorrido por el distrito considerado el más artístico de Lima.

A la mañana siguiente, José, Walter y yo nos encontramos para hacer un recorrido por varios talleres en el marco del Barranco Open Studios, iniciativa que busca reunir el turismo y la cultura permitiendo al público ingresar a los talleres de los artistas dedicados a diferentes especialidades en el campo de las artes. Fue gratificante e interesante tener la oportunidad de acceder y conocer los diferentes espacios ubicados en antiguas casonas barranquinas, donde artistas de diferentes escuelas, especialidades, egresados, estudiantes y autodidactas crean día a día obras de arte. Aparte de las visitas que realicé, pude conversar con muchos de ellos sobre sus obras, metodología de trabajo, motivaciones y aspiraciones. Debo admitir que me impactó el feeling que emanaba de estos talleres donde se vive y se siente el proceso creativo, sin límites, expresado en temas, materiales, experimentación, etcétera.

Desde un punto de vista sensible, el arte expuesto en los talleres que visité mostraba libertad, vida propia, a manera de seres imaginario-corpóreos en movimiento. Muchas de las obras estaban en proceso de creación, lo que hacía posible apreciar su desarrollo. Toda la experiencia iba más allá de la admiración estética; percibí una energía que alimentaba mi alma haciéndome recordar y añorar los días de taller que dejé tiempo atrás.

Esa misma tarde, continuando con la búsqueda de experiencias e información y bastante estimulada por lo acontecido durante mi recorrido barranquino, acudí junto a mis dos amigos a una feria de arte muy conocida en Chorrillos. Me sentí entusiasmada al ver la cantidad de obras de arte, artistas y galerías de todo el mundo en un mismo lugar, arriesgándose a ser juzgados por los espectadores y posibles compradores de arte. Debo mencionar que el lugar es impactante: se puede comer, beber, juntarse con los amigos o ir en familia para pasar un buen momento.

Nuestro recorrido comenzó de manera muy animosa; esperábamos encontrar diversidad en las propuestas artísticas, nuevas tecnologías y temáticas, además de ese feeling tan estimulante y hasta divino que experimenté por la mañana. Mientras caminábamos por los pasillos, veíamos galerías que exponían obras novedosas e inspiradoras, 
pero también muchas otras que mostraban diferentes creaciones con atributos comunes entre sí. Esta situación me hizo suponer que había una tendencia a mostrar obras concebidas bajo la influencia de cierto tipo de estética.

Para muestra un botón: en varias galerías proliferaban obras de diferentes artistas en mediano y gran formato forradas totalmente en pan de bronce, oro o aluminio, al parecer con la técnica del esgrafiado que dejaba ver la base de color blanco. Visualmente eran lindas, decorativas y cumplidoras si nos referimos a la decoración de un espacio. A lo largo de la tarde, esta situación se repitió con otras obras de particular estilo, que se veían repetidas continuamente en diferentes galerías, pero eso no era nada comparado con lo que sucedió a continuación. Fue una situación especial y surreal la que vivimos al ubicar un par de obras de diferentes artistas que eran idénticas, parecían gemelas; quedé atónita y con la duda de qué se estaba considerando arte en la mencionada feria, puesto que por momentos la sensación que me dejaba era de que las obras habían sido concebidas para que el espectador hallase en el arte un fin práctico y decorativo. En ese instante, recordé las entrevistas a Kuspit y a Furió. Salí de la feria, era de noche y me sentía agotada de tanto arte.

Luego de una prudente cantidad de días, en los que me dediqué a analizar las entrevistas y ambas experiencias, con la computadora encendida para descargar todo lo acontecido, no pude dejar de preguntarme: ¿qué es arte?, ¿el arte es puro sentimiento y llega al alma originando una reacción estimulante?, ¿es acaso el propósito del arte ser decorativo y cumplir con ciertas reglas de estética que se sabe que van a garantizar el éxito de compra y venta de manera mecanizada durante la creación de una obra?

\section{DEFINICIÓN DE ARTE}

Ante las preguntas planteadas, segura de la existencia de varias definiciones de autores que tratan el tema desde diferentes ángulos, decidí que debía ordenar mis ideas y empezar por el inicio, es decir, encontrar un concepto general para el arte, a manera de punto de partida. Me detuve en la definición de arte que plantea la Real Academia Española: es la manifestación de la actividad humana mediante la cual se interpreta lo real o se plasma lo imaginado con recursos plásticos, lingüísticos o sonoros. La definición me pareció simple, no llenaba mis expectativas.

Acudí a la biblioteca de Miraflores, ubicada en el Centro Cultural Ricardo Palma, para encontrar más información que me ayudara a ampliar dicho concepto. Después de toparme con libros muy bonitos, de tapa dura e imágenes en muy buena resolución que llamaban mi atención, encontré una repisa que contenía libros de autores que habían escrito sobre arte, su significado, características, problemáticas, actualidad, mercado, etcétera. 
Hojeando el primer libro, hallé una definición escrita por Hugo Hiriart (1999), donde define el arte, incluido el arte actual, como una noción que todos conocemos, reconocemos y apreciamos, pero que tiene la particularidad de ser subjetiva, al mismo tiempo que resulta difícil explicarla porque es uno de esos conceptos que aprendemos por medio de la práctica. A lo largo de la lectura, el autor se anima a formular una descripción conceptual basada en el trabajo humano y la intromisión de dos elementos comunes y enfrentados que, según su opinión, caracterizan el arte. Estos elementos son la creatividad, entendida como la inventiva que diferencia una obra de arte de una artesanía, y la tradición. "Definamos arte, entonces, como el trabajo en el que se inventa dentro de una tradición modificándola de manera personal" (Hiriart, 1999). Las obras se sitúan en un contexto particular o, como él indica, en una tradición que produce en ellas una singularidad que abarca el modo y estilo, equivalente al modelo, que acompaña su creación.

A continuación, leyendo a Vasili Kandinsky (2018), el artista coincide con Hiriart (1999) en que el arte nace y se desenvuelve en un contexto histórico y artístico particular, dentro de una sociedad que está conformada por formas culturales que proporcionan elementos y significados para la creación. En tal sentido, Kandinsky agrega que la obra de arte es la expresión de un artista que sale de la subjetividad con la intención de exteriorizar por medio de un estilo propio, formado en la época en la que habita, convirtiéndose en receptor y a la vez emisor de su tiempo. También indica que el contexto histórico, que contiene a un artista y su obra, nos presenta dos tipos de creaciones: las que desaparecen cuando el entorno en el que se conciben tiende a desvanecerse, puesto que su mira es la de reflejar la atmósfera del momento sin la capacidad de evolucionar; y aquellas que, según lo que él denomina "época espiritual", se basan en algo más que plasmar hechos o reflejos de lo que se vive en su época. Se trata de un acontecimiento que se encuentra en el arte y al mismo tiempo recibe de este sus mayores aportes, adoptando formas artísticas que manifiestan un sentir que perdura y trasciende generaciones. Es en lo espiritual del arte, en el sentir, donde se encuentran las similitudes artísticas de obras concebidas en diferente tiempo, espacio y ubicación geográfica; de otro modo, serían consideradas copias sin vida. Es, para Kandinsky, "la igualdad en la aspiración espiritual”, "la igualdad en el sentir interno".

De acuerdo con José Luis Barrios (1999), tratar de encontrar un significado, teorizar y dar características al arte ha llevado a la distorsión de lo que él considera la vivencia estética. Al respecto, plantea que esta es una situación propia de nuestra era, pues, si nos remontamos al pasado, encontramos que en la antigüedad la religión, política, moral, arte y estética convivían al mismo tiempo, ya que las sociedades eran totalitarias. En cambio, la relación que mantiene la imaginación con la realidad que se vive actualmente ha llegado a generalizarse ampliando el esteticismo hasta el punto de hacer valer todo. Influenciado por los acontecimientos de cada época, el ser humano se vuelve un personaje activo de su realidad por medio de su imaginación y de las metáforas manejando 
su propia vivencia estética. Es así como esta experiencia se convierte en un acceso a la historia de la humanidad.

En la vivencia estética adviene un mundo histórico, donde la historicidad no tiene que ver con la pertenencia de un objeto al pasado, sino con la forma en que la humanidad, una colectividad determinada, se relaciona con su entorno, y donde dicha relación se patentiza en obra. (Barrios, 1999)

En cuanto a hacer valer todo en el arte, como escribe Barrios (1999) y comenta en su entrevista Kuspit ("vale todo"), Mauricio Navia (1999) brinda indicios sobre la aparición de esta situación: para él, el vale todo (everything goes) tiene su origen en el contexto histórico de los años ochenta a manera de protesta. Los posvanguardistas estaban enfrentados con las vanguardias y todo lo que representaban; deseaban desligarse de las clasificaciones en el arte, de la estética, el mercado, la industria cultural, los antiguos lenguajes, el exclusivismo en el arte y los conceptos ortodoxos de ese entonces, para dar paso a nuevos lenguajes y estéticas, y de este modo abrir la cultura. En un principio, se creía que esta tendencia no iba a durar por diferentes motivos, entre ellos, la dificultad que las obras concebidas en este período presentaban para su exposición, así como el desinterés inicial del mercado y del público. Con el tiempo se demostró que este pronóstico fue errado, puesto que hasta la fecha su producción ha aumentado y se las aprecia en galerías, museos, bienales, etcétera.

¿Qué personajes o movimiento cultural artístico dio origen a estos cambios? Se manejan diferentes nombres. Hay quienes señalan a los dadaístas. Navia (1999), por su parte, baraja la idea de que comenzaron con Warhol y Beuys. A partir de entonces, se desplazaron, pero no eliminaron especialidades de las bellas artes tales como la pintura y la escultura, dando apertura al arte contemporáneo que alberga al grupo Fluxus, los happenings, el pop art, el arte conceptual, el land art, etcétera.

En realidad, casi todos los artistas juegan en libertad, con todas las cosas que están en juego en esta segunda mitad de siglo, desplazándose sin dramatizar entre performances, happenings, efectos neoconceptuales, bad paintings, sucesos minimalistas, superimágenes, cómic y pop, intervenciones urbanas y desespacializaciones de no lugares, lenguajes del mass media o de internet, efectos audiovisuales y deconstrucciones de otros lenguajes. (Navia, 1999)

\section{Diversificación de las artes}

Al día siguiente, antes de enrumbar hacia la biblioteca, encontré en mi casa un libro que mi madre me había traído de Washington hace años, en el que Martha Richler (1998) indica que en el contexto de los años setenta se venían cuestionando los conceptos y estilos del arte. En un momento dado, los artistas conceptuales de la época, con el objetivo de desestabilizar el mercado establecido, crearon obras en las que prevalecía la 
idea por sobre la ejecución, lo cual ocasionó que en un inicio fuera difícil su comercialización. Asimismo, surgieron los happenings (improvisaciones) para demostrar que la acción era lo que primaba en la obra, a tal punto que muchos de ellos fueron filmados en cintas de video convirtiéndose en parte de la obra por el material registrado.

Durante el posvanguardismo, gran parte de las obras concebidas poseían características que las hacían inadecuadas para exhibirse en una galería o en un museo, y por añadidura en sus inicios se cuestionaba su existencia como arte. Esto ocurrió con el land art: obras artísticas de tamaño monumental que utilizan el espacio como soporte y a los elementos contenidos en este como materiales para su construcción (Guasch, 2001). A su vez, el arte povera, influenciado por el movimiento hippie que surgió en el contexto histórico del Mayo francés o Mayo del 68, estaba en contra de la posición del arte como un producto con valor comercial; fomentaba la expresividad, creatividad y espontaneidad mediante el uso de materiales poco convencionales, no tecnológicos y de segunda mano (Guasch, 2001). Igualmente, se difundieron los grafitis, representaciones de imágenes provenientes en su mayoría de cómics y videojuegos que se realizaban en espacios públicos con la finalidad de expresar una identidad, a la par de manifestar oposición a la estructura social, política y económica del momento (Guasch, 2001).

\section{Nuevas tecnologías en el arte}

Para Sandra Barrera (2011), actualmente se aprecia que muchas obras de arte van más allá de la plástica. El uso de las nuevas tecnologías está ganando terreno en el proceso de dar vida a una obra de arte concebida en un contexto histórico complejo, con problemas sociales, políticos y ambientales, expresados en pobreza, guerra, desastres ambientales, entre otros. Estas nuevas tecnologías traen consigo la creación de trabajos con una fuerte carga conceptual, pero con una debilidad en lo formal. Además, asegura Barrera (2011) que la multidisciplinariedad que el arte experimenta con ciencias como la física, biología, robótica, informática, etcétera, se está haciendo más frecuente en el momento que el artista expresa mediante su creación. Para complementar la idea, Antoni Tàpies (1970) agrega que, aparte de los avances tecnológicos, los artistas se ven influenciados también por los avances de las ideologías y de las ciencias filosóficas, científicas y políticas.

La situación que plantea Barrera (2011) no difiere de lo que ha venido sucediendo a lo largo de la historia: cada época ha utilizado la evolución de la tecnología para crear obras con nuevos contenidos, soportes y materiales. En tal sentido, aclara que - con una mirada que va más allá del simple utilitarismo, el dominio de los materiales y el surgimiento de nuevas técnicas bajo la premisa de expresar algo mediante un lenguaje simbólico- el arte se ve influenciado por el contexto tecnológico a través del descubrimiento, la investigación, la experimentación, la comprobación y el uso de los nuevos conocimientos. 
El arte y su concepto han cambiado a lo largo de la historia debido a su medio, que lo convierte en generador de reflexiones sobre el individuo y la sociedad. Así, en la época prehistórica, el arte estaba ligado a lo místico, mientras que en la actualidad se ha vuelto difuso definirlo, en parte por las nuevas tecnologías y la multidisciplinariedad que ha adquirido con la ciencia (Barrera, 2011).

\section{Crítica del arte}

La dificultad que encuentra el arte actual para ser definido se debe a que en cada momento histórico y cultural el significado del arte y la figura del artista se han visto cuestionados. Joan M. Minguet (2010) observa que los libros de historia del arte presentan obras pertenecientes a diferentes épocas, que en su momento no eran consideradas como tales, pero que con el paso de los años el ser humano les ha dado cabida en lo artístico. De esta situación se desprende la apreciación de que muchas obras de la actualidad reciben la objeción por parte de críticos y entendidos, como parte del proceso de cambio en el que está sumergido el arte.

Si la figura del arte y la del artista cambian constantemente, es congruente pensar que sucede lo mismo con la del crítico. Así, lo encontramos ejerciendo funciones que van más allá de la emisión de un juicio u opinión sobre una obra o conjunto de obras; ahora se trata de un personaje que ha sabido ampliar su campo de acción con actividades relativamente recientes de la crítica, como la dirección de centros artísticos, la dirección y programación de ferias artísticas, las asesorías en la compra de obras de arte, las curadurías (es decir, la realización de proyectos de exposiciones acompañados, por lo general, de literatura, justificación, argumentos, aproximaciones teóricas o analíticas), los cursos o talleres, así como su participación como miembro de jurados que otorgan premios o becas (Minguet, 2010).

El estado actual del crítico de arte lo ha convertido en pieza clave, por medio de su faceta de curador, para la relación entre los artistas y los lugares expositivos, asegura Minguet (2010). Como curador deja atrás su imagen pasiva y se convierte en coprotagonista con el artista, en tanto que se encarga de todo lo vinculado con la exposición: la preproducción, la selección de obras que la componen - poseedoras de una carga artística o estética que apoyan la lectura de la exposición-, y el discurso expositivo basado en un discurso visual e intelectual plasmado en una ruta propuesta por este personaje, sin dejar de lado la ruta que el espectador realiza por sí mismo. En este punto, es necesario acotar que todo el trabajo efectuado por el curador no debe interferir con el proceso natural creativo del artista ni tampoco con su discurso personal. 


\section{CREACIÓN ARTÍSTICA}

Según indica Kandinsky (2018), para la creación de una obra el artista puede recurrir a simples sentimientos como la pasión, el miedo, la tristeza, la felicidad, etcétera, pero su estado natural y creativo lo obliga a buscar matices más intensos que representar para motivar al público espectador. Es así como la obra de arte puede y debe tener la capacidad de modificar el estado de ánimo de quien la observa, e incluso llegar a compenetrarse con el público haciéndolo captar el sentir y el punto de vista del artista.

Por otro lado, Barrios (1999) la describe como un objeto que representa el imaginario. La representación que se muestra se complementa con el entendimiento e imaginación del espectador, el cual confirma su existencia como un ente activo. Para su construcción, está involucrado un lenguaje artístico compuesto por elementos formales, tales como el color, la línea, las texturas, etcétera, así como la composición.

Teniendo en cuenta la evolución del arte y todos los sujetos que lo rodean, en un inicio los cuadros eran juzgados por lo que representaban y, posteriormente, por los signos plásticos que poseían. A este proceso Tàpies (1970) lo denomina "gusto de la época", y se da en cada etapa de la historia. La evolución que se experimenta en cada etapa supone un rompimiento con las anteriores establecidas; en tal sentido, describe al artista como el personaje que, consciente de su cultura y realidad, expresa su emotividad a través de sus obras.

Una obra, según indica Tàpies (1970), es más valorada que cualquier otra si conecta con la realidad. La permanencia de algunos estilos vigentes que no tienen relación con la realidad se ve protegida por ciertos factores y sobre todo por los que él denomina "guardianes de la tradición", como galerías, críticos, museos, bienales, etcétera, cuyo objetivo es incentivar y proteger la copia de formas ya conocidas y establecidas correspondientes a creaciones antiguas.

Kandinsky (2018) comenta, entonces, que los artistas motivados por el deseo de éxito crean obras bajo la premisa de seguir una estética segura, que involucra la mezcla constante de elementos y formas sin poseer un sentido o contenido verdadero. Incluso algunos artistas ofrecen obras donde el cómo (lenguaje del artista, composición, forma, color, etcétera) tiene más peso o validez que el qué (sustentación y significado fundados en la comunicación entre el artista y el espectador).

Este "qué" no es el "qué" material y objetivo de la época superada, sino un contenido artístico, el alma del arte, sin la que su cuerpo (el "cómo") no puede tener una existencia plena y sana, al igual que un individuo o un pueblo. (Kandinsky, 2018, p. 40)

Ante esta situación, encontramos artistas que prefieren emplear elementos débiles que mezclan continuamente, a tal punto que no necesitan decir mucho, sino que se lucen gracias a determinados círculos de mecenas y conocedores. Asimismo, Kandinsky (2018) 
asegura que los entendidos de las cotizaciones saben que el público desea encontrar en el arte esteticismos que abarcan desde formas simples, imitaciones de la naturaleza y estados de ánimo; por eso, las defienden y fomentan.

\section{MERCADO DEL ARTE}

Actualmente, se aprecia una singularidad que ha venido dándose en el denominado arte nuevo. Se trata de la intención de querer mostrarlo de manera impactante para venderlo y así llegar al éxito comercial. Para conseguir este objetivo, el artista encuentra un condicionamiento sutil relacionado con el mercado para la creación de sus obras, además de estar involucrados factores como los mass media y los personajes descritos por Tàpies (1970): los organizadores de exposiciones, periodistas, críticos, etcétera, encargados de otorgar un valor entendido como "cotización" de las obras, según parece, sobre la base de una serie de esteticismos vinculados con ingredientes extraídos del pasado, que funcionaron muy bien en su tiempo, con el objetivo primario de venta.

Lo que se nos quería hacer pasar por valores eran tan solo los ingredientes artísticos - si acaso los hay - y, en cambio, lo que verdaderamente cuenta ha sido siempre el pensamiento o los sentimientos que el autor nos ha querido comunicar. (Tàpies, 1970)

El mercado, con sus órdenes establecidos, facilita la creación de obras sin una función más allá que la de ser un producto decorativo.

Nunca he pensado que la obra de arte pueda formar parte algún día de la "decoración". Para mí, la obra de arte — sea lo que sea: cuadro, escultura, objeto o idea - tiene una individualidad propia, es algo que se basta a sí mismo. El hecho de que se cuelgue en una pared es accidental. (Tàpies, 1970)

Tàpies (1970) menciona una aparente vox populi que dice que muchas obras, luego de ser creadas, son intervenidas, pulidas, despolitizadas; en síntesis, las vuelven más interesantes y apetecibles bajo el criterio de popularizar el arte, con el objetivo de que ingresen a nuevos mercados para su venta. Como todo producto, según indica Eloísa del Alisal (2005), el mercado del arte depende de la situación global del momento, concretamente, de las situaciones políticas, sociales e, incluso, de la moda, que es otro factor condicional de las ventas.

Así pues, Del Alisal (2005) reconoce que el mercado del arte es el primero en verse afectado por acontecimientos como las guerras, mientras que si, por otro lado, la sociedad se encuentra en un estado de bonanza, este se eleva e incrementa sus costos, puesto que se trata de artículos deseados por muchos inversionistas y coleccionistas de arte. Son ellos los encargados de cuidarlos como mercancía, especulando sobre su valor y haciendo subir sus precios de manera escandalosa en algunas ocasiones. 
Dalia Haymann (2005) explica que el criterio comercial prevalece y se antepone a la creación del artista, quien, influenciado por la ley de la oferta y la demanda, deja de lado el valor real del arte y se concentra en el precio por el que va a venderlo a los coleccionistas, quienes ven las obras como una inversión. Son los coleccionistas privados, los art dealers, las galerías, los museos, las casas de subasta, etcétera, quienes mueven el mercado. El criterio con el que se mueve el mercado hasta la fecha ubica al impresionismo y a los old masters como productos codiciados en las diferentes plataformas donde son vendidos (Haymann, 2005). Al respecto, la autora describe cuatro espacios de ventas reconocidos:

1. Casas de subasta internacionales: dan la pauta en lo referente a las obras y precios.

2. Galerías nacionales, internacionales y ferias de arte: ven al artista que acogen como una inversión.

3. Independientes: con bastante aceptación entre el público joven que desea comprar arte, están conformados por art dealers, colectivos de arte, etcétera.

4. Experimentales: son espacios expositivos que se han abierto para la exhibición de diferentes tipos de arte; entre estos espacios están las plataformas virtuales.

\section{CONCLUSIONES}

Como indiqué al comienzo de este artículo, toda la información fue llegando a mí de manera violenta y desordenada, lo que al principio me causó un bloqueo respecto a determinar qué información recopilada iba a emplear. A esta situación se sumó el hecho de querer expresarme como artista, sin seguir un estilo en particular de escritura que limitara mi proceso creativo. Consciente de no estar siguiendo un estilo ortodoxo de redacción, pero al mismo tiempo liberada de esas ataduras, me aventuro a comunicar que después de las experiencias vividas y libros leídos para encontrar respuestas me quedan claras ciertas particularidades que ha compartido el arte en todos los tiempos. Así llegué a la conclusión de que el arte es un concepto que entendemos (subjetivamente), pero que es difícil de explicar sobre todo en estos tiempos en los que se ha diversificado tanto; nace en un contexto histórico particular, acompañando los acontecimientos de su época como un personaje activo de su realidad, a la vez que es receptor de toda la información y emisor de la misma para su lectura en el futuro; además, el arte usa la tradición y también la creatividad, se realiza de un modo y emplea un estilo. Todo lo descrito se complementa con la afirmación de que el arte posee espíritu y alma en el momento de su creación.

En un inicio, dudé si esta definición pudiera ser aplicable a todas las artes, en especial al arte de posvanguardia y al actual. Pero encontré que de igual manera estos 
dependían de un contexto histórico, en este caso, motivado por el deseo de los artistas de expresar su sentir y oposición a la estructura social, política y económica, así como su cuestionamiento sobre los conceptos y estilos ortodoxos del arte. Esto propició la creación de obras por medio del descubrimiento, el desarrollo y la diversificación de las artes que empleaban nuevas prácticas y tecnologías.

Las denominadas nuevas tecnologías son consecuencia de la evolución de la humanidad y pueden ser usadas en el arte si la obra lo amerita. Claro está que para un sector más clásico del arte esto no es posible, pero cuando nos referimos a la creación artística no podemos obviar la evolución que el arte y su entorno han tenido para ajustarse a los nuevos tiempos.

Considero que se debe tener presente que, sin importar el soporte o tema que el artista desee tratar, la creación artística tiene un propósito que va más allá de la copia o representación de sentimientos vulgares, e incluso de esteticismos planteados para garantizar su venta. El objetivo del arte es comunicar, hacer sentir, vibrar, etcétera. Lo cierto es que en el camino nace la pregunta: ¿creo una obra para venderla o la hago para expresar, así no venda nada? Algunos responderán: para vender, pero en ese momento se estará creando una obra sin vida, sin contenido que, en el mejor de los casos, con una ayudita de ciertos factores (galerías, curadores, artistas, mecenas, compradores de arte) puede tener el "éxito" garantizado. Otros se decidirán por crear para comunicar, para hacer vibrar a un público, aunque eso signifique que sus obras "no sean vendibles" (así le respondió una galería muy conocida a un amigo que hace videoarte e instalaciones).

En tal sentido, es decisión de cada artista bajo qué sello quiere ser recordado a lo largo de los años. Lo interesante es que, si estamos presenciando la muerte de un arte superficial, vacío y sin vida, nos tocará ver, vivir y participar de su resurgimiento.

\section{REFERENCIAS}

Barrera, S. (2011). Arte en el siglo XXI. ¿Para qué sirve el arte contemporáneo? De la ciencia de Stephen Wilson al misticismo de Mariko Mori. El Astrolabio. Revista de Investigación y Ciencia del Gimnasio Campestre, 10(1), 56-62. Recuperado de http:// edicionesanteriores.revistaelastrolabio.com/ediciones-anteriores/volumen _10-1/astrolabio-10_1-4

Barrios, J. L. (1999). Cuerpo y percepción: subjetividad y escritura de la historia del arte. En L. Enríquez (Ed.), XXII Coloquio Internacional de Historia del Arte. (In)disciplinas: estética e historia del arte en el cruce de los discursos (pp. 69-91). Ciudad de México: Universidad Nacional Autónoma de México, Instituto de Investigaciones Estéticas. 
Del Alisal, E. (2005). Arte y mercado. Una aproximación. Boletín GC: Gestión Cultural, 12. Recuperado de https://studylib.es/doc/1836057/arte-y-mercado--unaaproximacion

Guasch, A. (2001). El arte último del siglo xx. Del postminimalismo a la multiculturalidad. Madrid: Alianza Editorial.

Haymann, D. (2005). Mercado del arte. Boletín GC: Gestión Cultural, 12. Recuperado de https://studylib.es/doc/1836054/mercado-del-arte

Hiriart, H. (1999). ¿Qué es el arte? Una definición. En L. Enríquez (Ed.), XXII Coloquio Internacional de Historia del Arte. (In)disciplinas: estética e historia del arte en el cruce de los discursos (pp. 123-127). Ciudad de México: Universidad Nacional Autónoma de México, Instituto de Investigaciones Estéticas.

Kandinsky, V. (2018). De lo espiritual en el arte. Recuperado de http://www.elboomeran. com/upload/ficheros/obras/1303_kandinsky.pdf

Minguet, J. M. (2010). De la crítica de arte a la práctica curatorial. Algunas reflexiones. Disturbis. Recuperado de https://ddd.uab.cat/pub/disturbis/disturbis_a2010n8/ disturbis_a2010n8a6/disturbis_a2010n8a6.pdf

Navia, M. (1999). Territorios del arte y la estética. En L. Enríquez (Ed.), XXII Coloquio Internacional de Historia del Arte. (In)disciplinas: estética e historia del arte en el cruce de los discursos. Ciudad de México: Universidad Nacional Autónoma de México, Instituto de Investigaciones Estéticas.

Richler, M. (1998). Capítulo undécimo. Finales del siglo xx. En Un mundo de arte. National Gallery of Art Washington (pp. 206-218). Londres: Scala Books.

Tàpies, A. (1970). La práctica del l'art. Barcelona: Ariel. 